\title{
Impact of internal migration on fertility in Cotonou, Benin Republic
}

\section{Boladé Hamed Banougnin ${ }^{1}$, Adeyemi O. Adekunle ${ }^{2}$, Adesina Oladokun ${ }^{2}$ \& Mouftaou Amadou Sanni ${ }^{3}$}

${ }^{1}$ Pan African University, Life and Earth Science Institute (Including Health and Agriculture), University of Ibadan, Ibadan, Nigeria

${ }^{2}$ University College Hospital, Department of Obstetrics and Gynaecology,

University of Ibadan, Ibadan, Nigeria.

${ }^{3}$ Ecole Nationale de la Statistique, de la Planification et de la Démographie,

Université de Parakou, Parakou, Bénin

Email: Hamed.Banougnin@outlook.com

\begin{abstract}
Context/Background: In developing countries, fertility is usually higher in rural than urban areas. This is partly due to lower access to and utilization of reproductive health services in rural areas. However, migration to cities may alter the fertility behaviour of migrants from rural areas.

Data Source and Methods: The study used 2012 Benin Republic Demographic and Health Survey data and focused on married women aged I5-49 years and residing in Cotonou $(n=722)$. Tobit regression was employed for the multivariate-level analysis.

Findings: The results showed that migrants adapt gradually to the fertility patterns of non-migrants. This gradual adaptation is compounded by a relative selectivity of migrants whose fertility preferences are similar to those of non-migrants. Finally, recent migrants for employment or school reason had the lowest number of births over the past five years, which supports the disruption hypothesis.

Conclusion: The migration-fertility relationship depends on the length of residence, migrant' socioeconomic characteristics and reason for migration.
\end{abstract}

Keywords: Migration; fertility; urban areas; Cotonou; Benin Republic.

\section{Introduction}

In sub-Saharan Africa countries, fertility rates are lower in urban than in rural areas (Garenne, 2013; Gries \& Grundmann, 2015; Flückiger \& Ludwig, 2017; Mberu et al., 2017). The lower fertility level in cities is however under threat, because of the rapid and uncontrolled urbanization many sub-Saharan Africa countries are facing (United Nations, 20/4). Various factors could explain the lower fertility rates in urban areas (Shapiro \& Gebreselassie, 2013; De Brauw et al., 20I4; Benza et al., 2017; Jedwab et al., 2017). On the one hand, following the International Conference on Population and Development (ICPD), held in 1996 in Cairo (Fincher, 1994), the most beneficial policies in terms of family planning and woman's sexual and reproductive rights were primarily implemented in urban areas (Coburn et al., 2017). These policies were previously successfully implemented in Europe for the fertility decline purpose (Zinkina \& Korotayev, 20I4). Sub-Saharan Africa urban centres have thus inherited policies strongly supportive of adequate sexual and reproductive health in urban areas. So, the urban environment has historically been characterized by a wide access to sexual and reproductive health services. On the other hand, urban dwellers benefit 4305 from higher social and economic status than their peers living in rural areas (Michel \& Ribardière, 2017). In other words, the lower fertility rates in urban areas are both due to the historical context inherited from developed countries and the higher socioeconomic conditions. However, it is not enough to compare fertility rates between urban and rural areas as if they were disclosed separately. Indeed, they (urban and rural areas) are affected by substantial migration flows. Migration can generate an increase of sexual and reproductive health services utilization (Ellawela et al., 2017) and a decline of fertility level (Williams et al., 2013; Anglewicz et al., 2017). The main objective of this study is to examine the extent to which fertility varies with migration status in Cotonou, the largest city of Benin Republic.

The population of Benin Republic rose from $6,769,914$ persons in 2002 to $10,008,749$ persons in 2013 - year of the last national census (INSAE, 20I6). As in other sub-Saharan Africa countries, the urbanization rate increased from 34 per cent in 1990 (United Nations, 20I4) to 45 per cent in 2013 (INSAE, 2016). According to demographic projections of the United Nations (20I4), the urbanization rate will very probably reach a level of http://aps.journals.ac.za 
61 per cent in Benin Republic by 2050. Despite the lack of updated data on migration flows between urban and rural areas, Engel et al. (2017) have shown that urban growth is mainly driven by migration from rural areas. In the area of fertility behaviour, the total fertility rate is lower in urban than in rural areas (INSAE \& ICF International, 20I3; INSAE, 20I6). This urban-rural difference in fertility seems to reflect the difference of contraceptive prevalence. The modern contraceptive use is higher in urban than in rural areas (INSAE \& ICF International, 20I3). Low-level of reproductive health knowledge and low levels of access to reproductive health services as well as poverty and environmental factors are among major elements that underline the high fertility rate in rural areas (Odimegwu \& Somefun, 2017; Wulifan et al., 2017). In contrast, urban areas are characterized by a relatively higher access to and availability of reproductive health services, high access to media and school facilities (Chintsanya, 2013). Moreover, the high cost of living in urban place makes families encounter increased family maintenance cost which may be a source of low fertility preference among urban inhabitants (Gries \& Grundmann, 20I5; Mberu et al., 2016; Benza et al., 2017).

This study is an attempt to bring to light a full account of the effects of internal migration on fertility in Cotonou, the largest city of Benin Republic. The conceptual framework and hypotheses of the study are first presented. Then, data and analysis methods, as well as the findings are presented. Finally, the findings are discussed before any conclusions.

\section{Literature review and conceptual framework}

Studies on migration and fertility relationship have been conducted for several decades and have led to various models summarized as partly complementary and contradictory hypotheses: the socialization hypothesis, the adaptation hypothesis, the selection hypothesis and the disruption hypothesis (Singley \& Landale, 1998; Kulu, 2006). These hypotheses have contributed to a better understanding of fertility and contraceptive use differentials between migrants and non-migrants (Majelantle \& Navaneetham, 2013; Rokicki et al., 20l4; Afulani \& Asunka, 2015; Anglewicz et al., 2017). The present literature review is however focused on how these hypotheses could be verified in the context of migrations to urban areas or lower fertility regions. The socialization hypothesis is not evoked in this study.

\section{Adaptation hypothesis}

The adaptation hypothesis postulates that the low fertility level and high contraceptive adoption among migrants in large cities are mainly due to their adaptation to the new environment (Chattopadhyay et al., 2006; Beine et al., 2013; Majelantle \& Navaneetham, 2013; Afulani \& Asunka, 2015; Anglewicz et al., 2017; Babatunde \& Ibukun, 2017; Dupray \& Pailhé, 2017; Pailhé, 2017). This hypothesis supports that migrants' fertility is assumed to be lower than that of stayers in rural areas, but similar to that of urban natives with comparable conditions (Majelantle \& Navaneetham, 20I3). The similarity of fertility rates between migrants and non-migrants in urban areas may be mainly due to the multiple constraints and dominant life conditions in cities (Ochako et al., 2016). These conditions are generally favourable to low fertility and high family planning utilization. Various theories underline the adjustment of the migrants' fertility behaviours to the fertility patterns of the urban destination environment. Some of these theories are derived from the microeconomic theories of fertility (Brockerhoff \& Eu, 1993; Avogo \& Agadjanian, 2008). The other ones are relatives to certain sociological and anthropological theories, particularly that of assimilation recently highlighted by Afulani and Asunka (2015). The authors have suggested that adaptation of sub-Saharan African migrants in France to low fertility ideals was strongly supportive of assimilation theory. Essentially, adaptation perspective points the conditions at the place of destination as a key determinant of migrants' fertility.

One of the major and initial support of the adaptation model was revealed in a work carried out by Brockerhoff and Yang (1994) in a purely African context. Their comparative study on rural-urban migrants in six sub-Saharan Africa countries indicated that migrants' chance of childbearing declined in all countries around the time of migration. Then, the odds of childbearing remained low in the long run among most migrant groups. Additional analyses completed later by the principal author have shown that the decline in migrants' fertility could be largely attributed to two main causes: a pronounced improvement in the standard of living after migration and the increasing use of modern contraceptive methods (Brockerhoff, 1995; Brockerhoff, 1998). The author has also confirmed previous findings by showing, for example, how the higher cost of childrearing may lead to low fertility among migrant women in cities.

In an urban environment characterized by high cost of living and greater media exposure (Kamruzzaman \& Hakim, 2015), migrants develop adaptation strategies conducive to low childbirths (Ochako et al., 2016). However, there may be a delay in the adaptation time. This is due to the time it could take for migrants to learn more about their new environment and expand their range of social contacts (Uprety et al., 2016). In consequence, we 
primarily expect migrants to have higher fertility than non-migrants in Cotonou, especially few times after the migration (Hypothesis la). Differences between migrant groups are also assumed to vary depending on the time spent by the migrant in urban areas. Here, women who migrated within the last 10 years (recent migrants) are expected to have higher fertility than those who experienced the migration more than 10 years ago (earlier migrants). The latter are assumed to have adapted to the new situation and therefore may not differ significantly from the nonmigrants in Cotonou (Hypothesis Ib).

\section{Selection hypothesis}

The association between migration and fertility behaviours has also been evaluated from the perspective of the selection model (Majelantle \& Navaneetham, 20/3). The selection model suggests that migrants are self-selected and represent a nonrandom sample in respect to their life cycle and their socio-economic characteristics; which predispose them to a specific fertility pattern (Agadjanian et al., 201 I; Rokicki et al., 2014). It particularly supports that the lower fertility among rural-urban migrants is mainly due to their higher socio-economic and sociodemographic status (Chattopadhyay et al., 2006). Migrants in cities are generally well-educated, often have well-paying job opportunities, which can lead to a delay in childbearing (Chattopadhyay et al., 2006; Rokicki et al., 2014; Marcén et al., 2016). Examining the effect of culture on migrants' fertility in the United States of America, Marcén et al. (2016) have shown that dissimilarities in education and employment status play a major role. Their findings suggested that it appears socially more acceptable for women with high socio-economic status to have fewer children than those with a lower one. So, positive selection of migrants in cities with high socioeconomic status may be the principal source which accounts for their lower fertility in urban areas. Indeed, the latter's fertility preferences are lower than those of stayers in rural areas and more similar to those of people at the urban destination.

The selection hypothesis has also been highlighted by Rokicki et al. (20/4) in a study undertaken in Accra, Ghana. The authors have looked for the association between migration and pregnancy outcomes among women residing in the urban slums of Accra. They have found that the completed fertility patterns of lifetime Accra residents were remarkably similar to those of residents who migrated. The authors have also attributed this to the specific high socio-economic status of women who migrated to Accra. In addition, Chattopadhyay et al. (2006) distinguished two categories of migrant women: the ones who have high fertility intentions and thus migrate to rural areas, and the other ones who desire fewer children and consequently migrate to large cities. Therefore, the choice of the place of destination of the migrants could not arise from a random process but rather determined by a definite objective regarding family size preference. Ultimately, the selection model seems to explain fertility differences by the selective effect of migration. This selective effect is in accordance with the adoption of the subsequent fertility or contraceptive use outcomes at the place of destination (Ochako et al., 20I6).

Moreover, the selection model has been identified in some earlier work, to be linked to that of adaptation in particular as regards migrants' fertility as well as their contraceptive practices (Chattopadhyay et al., 2006; Lindstrom \& Hernández, 2006; Rokicki et al., 20I4; Ochako et al., 2016). Chattopadhyay et al. (2006) have incriminated the role played by both adaptation and selection to explain the fact that rural-urban migrations slowed down the fertility rate of Ghanaian women in cities. Similarly, Rokicki et al. (2014) reported such relationship in a study undertaken among migrant women and native ones in Accra, but to a lesser extent. In their research, the main factor of the low fertility of immigrant women in Accra was attributed to the high prevalence of abortion. So, the selection and adaptation hypotheses may be complementary. Especially, migrants from rural areas can adapt to the urban areas fertility pattern which is affected by the high cost of living. In addition, their socio-economic characteristics which account for the selection can reinforce the adaptation process. Like any other countries, the migrant women in Cotonou are supposed to have socio-economic characteristics relatively similar to those of urban non-migrant women. That being so, it is expected a non-significant (or a weak) difference between migrant and nonmigrant women in Cotonou (Hypothesis 2).

\section{Disruption hypothesis}

The disruption hypothesis assumes that the changes relative to migration events induce low fertility at least in the short-term. This hypothesis has found support in many studies, especially in a study conducted by Goldstein and Tirasawat (1977). The hypothesis of disruption constitutes an explicative approach, different from the previous ones (adaptation, selection, and socialization hypotheses). The mechanism of action of the disruption hypothesis is strongly based on the "collateral" effects of migration on the whole behavioural change. It states that migration to city is often along with changes, which somehow may induce a perturbation in women reproductive life course, and then a fertility 
reduction (Andersson, 2004; Chattopadhyay et al., 2006; Majelantle \& Navaneetham, 20/3). In the literature, the observed and potential causes of disruption are complexes and numerous. One evokes generally the temporary separation of spouses (Cau, 2016); which leads to a "forced" absence or a diminution of the frequency of spousal sexual intercourses (Hervitz, 1985; Majelantle \& Navaneetham, 2013). Consequently, temporary migrants may have a short-term decline in the number of childbirths (Hervitz, 1985; Majelantle \& Navaneetham, 2013).

This mechanism has been identified by Sargent and Cordell (2003) in a study among women whose husbands migrated from Mali to France. Philibert et al. (20/3) have also highlighted this mechanism through a birth seasonality analysis among migrant women in the Kayes region, Mali. Their analyses showed that the fertility level of seasonal migrants was not very different from that of non-migrants at the destination place. They have also found that recent migrants' fertility level was considerably lower than non-migrants' one. They attributed this phenomenon to a possible disruption effect, resulting from spousal separation. Another reason often cited in the literature is the psychological distress state after migration. Indeed, psychological distress caused by migration may inhibit the mechanism of ovulation or the sexual libido (Byass et al., 20I I); which delays childbearing. Socio-economic constraints during the first years after migration to city is also a probable cause of disruption in reproductive life through delay in marriage and parenthood (Yabiku et al., 2010; Agadjanian et al., 20I I).

However, spousal separation due to migration remains the most important factor of disruption and the most cited in the literature (Yabiku et al., 2010; Agadjanian et al., 20 I I; Byass et al., 201 I; Philibert et al., 20I3). Agadjanian et al. (20II) found in rural Mozambique context, a fall in fertility among women whose husbands migrated for labour reason. Thereafter, the authors brought evidence of an increase in the rhythm of conception after the termination of the migration of the husband. So, according to the disruption model, fertility differentials between migrants' and non-migrants' wives should further be explained by the differential in the frequency of sexual intercourses. Moreover, in other contexts, the disruption may also cause an increase in conception risk, unintended pregnancies and potentially, abortion, in cases of extramarital sexual intercourses (Rokicki et al., 20l4). In this study, recent migrant women for job or school motive are expected to have lower fertility than nonmigrant and earlier migrant women (Hypothesis 3 ).

\section{Data and methods}

\section{Source of data}

This study uses data from the 2012 Benin Republic Demographic and Health Survey which is a nationally representative survey. From the 17,422 households interviewed, 16,599 women aged 15-49 years were interviewed among 17,329 found to be eligible, giving a response rate of $96 \%$ (INSAE \& ICF International, 20I3). Data on migration (for all the household members) were collected through the household questionnaire. Questionnaire for individual women contained reproductive health, some socio-economic and socio-demographic information specific to women of childbearing age (I5-49 years). Contrary to many DHS surveys, a huge section was especially devoted to migration information in the 2012 Benin Republic DHS. Identification variables (cluster number, household number, and household member's line number) are used from both households and women datasets to merge information in order to obtain a unique database. This analysis is restricted to the 722 women married at least five years before the survey and living in Cotonou (the largest city of Benin Republic) at the moment of the survey. Those women are generally more exposed to childbirths in the last five years preceding the survey. Migrant women who spent less than five years in Cotonou are excluded from this analysis. They were not completely exposed to the five years exposure of fertility in Cotonou.

\section{Dependent variable}

The dependent variable of the study is the number of children a woman has given birth to, during the last five years prior to the survey. The major advantage of this specific fertility indicator is that it enables to compare almost all women for the same period of exposure (which is five years in this study). Moreover, it gives more idea on birth intervals which are important because of its well-known association with higher child and maternal mortality. This dependent variable is quantitative although it may have some properties which are emphasized in the next section (2.4). Indeed, the number of live births in five years is limited and in between a specific finite interval.

\section{Independent variables}

The principal independent variable of the study is the migratory status. The migratory status can be determined through the following information collected in the household questionnaire (for every member) at the moment of the survey: current place of residence, place of birth, previous residence, duration of residence in the current location and motive for living at the current location. 
Migrant women in this study are women who were living in Cotonou for 6 months or more before the survey and who were residing somewhere else previously. Migrants are then classified into two types: recent migrants and earlier migrants. Migrants who spent no more than ten years in Cotonou at the time of the survey are considered as recent migrants; whereas those who spent more than ten years are considered as earlier migrants. This classification helps to take into account the duration of migration in the analyses as suggested by many researchers when studying the relationship between migration and fertility (Zamwangana, 2005).

The other independent variables of the analyses are: (I) educational level, (2) fertility preference which is measured by the ideal number of children according to the woman, (3) contraceptive use and (4) religion. The variable of motive for living at the current location is used as an interaction variable with the migration status variable.

Table I: Distribution of the dependent variable and independent variables: mean and standard error

\begin{tabular}{|c|c|c|c|c|}
\hline \multirow[t]{2}{*}{ Variables } & \multicolumn{2}{|c|}{$\begin{array}{c}\text { Number of births in last } 5 \\
\text { years preceding the }\end{array}$} & \multicolumn{2}{|c|}{ Observations } \\
\hline & Mean & Standard error & $\mathrm{N}$ & Percent \\
\hline \multicolumn{5}{|l|}{ Migratory status } \\
\hline Non-migrant & 0.8 & 0.0 & 402 & 41.0 \\
\hline Recent migrant & 1.1 & 0.1 & 226 & 23.1 \\
\hline Less recent migrant & 0.9 & 0.0 & 352 & 35.9 \\
\hline \multicolumn{5}{|l|}{ Educational level } \\
\hline No education & 1.0 & 0.0 & 326 & 33.3 \\
\hline Primary & 0.9 & 0.0 & 337 & 34.3 \\
\hline Secondary or higher & 0.8 & 0.0 & 317 & 32.4 \\
\hline \multicolumn{5}{|l|}{ Ideal number of children } \\
\hline Less than 4 & 0.7 & 0.0 & 346 & 35.3 \\
\hline 4 or above & 1.0 & 0.0 & 634 & 64.7 \\
\hline \multicolumn{5}{|l|}{ Contraceptive use } \\
\hline No method & 0.8 & 0.0 & 783 & 79.9 \\
\hline Traditional & 1.0 & 0.1 & 74 & 7.5 \\
\hline Modern & 1.0 & 0.1 & 123 & 12.6 \\
\hline \multicolumn{5}{|l|}{ Religion (Muslim or not) } \\
\hline Muslim & 0.9 & 0.1 & 142 & 14.4 \\
\hline Non-Muslim & 0.9 & 0.0 & 839 & 85.6 \\
\hline Total & 0.9 & 0.0 & 980 & 100.0 \\
\hline
\end{tabular}

$\mathrm{N}=$ wighted observations

\section{Methods}

The first phase of descriptive analyses involves comparing age-specific fertility rates (ASFRs) and the total fertility rate (TFR) by migration status. The rates are presented for the period of five years preceding the survey, determined from the date of the interview and a child's birth date. A five-year period is chosen for calculating these rates to provide the most current (short-term) information, to reduce sampling error. This reference period also reflects that of the dependent variable of the study. The ASFRs and TFR are computed using a Stata software module developed by Schoumaker (20I3). The second phase consists of presenting the number of births in the last five years preceding the survey by socio-economic and socio-demographic characteristics, and according to the migration status.

Then, a multivariate analysis based on Tobit regression is used to determine the effect of internal migration (as well as other socio-economic and sociodemographic factors) on fertility. Tobit regression is used for the "limited" nature of the quantitative dependent variable. The number of births in the last five years preceding the survey is a limited dependent variable which is quantitative for some of its range. But it is more censored in zero as many women gave birth to no child during the five years prior to the survey. For such variable, Tobit model adjusts for censoring using the probability of a person to being censored (Bourbonnais, 2009). Since the dependent variable is more censored in zero, the observations of 
the Tobit model used in this study are left-censored. In consequence, a single limit specified for the analysis is a zero lower limit. Coefficients obtained from the results of a Tobit regression can also be interpreted as marginal effects (Jann, 20I4).

\section{Results}

Current fertility rates for the five years preceding the survey, and by migration status are presented in Table 2. The results indicate that the TFR is lower among non-migrants (5.0 births per woman) than among recent migrants and earlier migrants (6.2 and 5.5 births per woman respectively). This means that, on average, non-migrant women in Cotonou will give birth to 5.0 children by the end of their childbearing years. Non-migrant women's TFR is 0.5 and 1.2 children less than that of earlier migrant women and recent migrant women respectively. Ag-specific fertility rate peaks in the 20-24 age group among non-migrants and earlier migrants (249 and 317 births per I,000 women respectively). Among recent migrants, ASFR reaches its maximum in the $15-19$ age group (325 births per 1,000 women) and declines thereafter.

Migrant women have higher TFR than nonmigrant women, with some differences in ASFRs in the intermediate age categories. The significant variations are in the 20-24, 25-29 and 30-34 age groups. In the 20-24 age group, recent migrant's ASFR is 14 and 68 births per thousand higher than that of non-migrants and earlier migrants respectively. Non-migrants and earlier migrants aged 25-29 years have respectively 52 and 25 births per thousand less than recent migrant women group. In the group of women aged 30-34 years, the ASFR for recent migrants exceeds that for non-migrants (respectively earlier migrants) by 50 births (respectively 63 births) per 1,000 women. Adolescent fertility among recent migrants almost doubles that among non-migrants (although nonsignificant) and more than doubles that among earlier migrants (although non-significant).

Table 2: Age-specific and total fertility rates for the five years preceding the survey, by migration status, Cotonou 2012

\begin{tabular}{|c|c|c|c|c|c|c|}
\hline \multirow{2}{*}{$\begin{array}{l}\text { Age } \\
\text { group }\end{array}$} & \multicolumn{2}{|c|}{ Non-migrant } & \multicolumn{2}{|c|}{ Recent migrant } & \multicolumn{2}{|c|}{ Less recent migrant } \\
\hline & ASFR (\%) & SE (\%०) & ASFR (\%०) & SE (\%०) & ASFR (\%) & SE (\%०) \\
\hline $15-19$ & $184^{(\mathrm{ns})}$ & 101 & 325 & 110 & $121^{\text {(ns) }}$ & 86 \\
\hline $20-24$ & 249 & 41 & 263 & 39 & 317 & 54 \\
\hline $25-29$ & 239 & 26 & 291 & 34 & 264 & 31 \\
\hline $30-34$ & 154 & 20 & 204 & 35 & 217 & 24 \\
\hline $35-39$ & 124 & 20 & 95 & 29 & 111 & 19 \\
\hline $40-44$ & 57 & 19 & $54^{(\mathrm{ns})}$ & 32 & 69 & 18 \\
\hline $45-49$ & - & - & - & - & - & - \\
\hline TFR & 5.0 & 0.6 & 6.2 & 0.7 & 5.5 & 0.6 \\
\hline
\end{tabular}

(ns) $=$ p-value $>1 \% ;$ ASFR = Age-specific fertility rate; TFR = Total fertility rate; SE = Standard Error

Figure I (box plot) presents, by migration status, the number of births in the last five years preceding the survey by socio-economic and socio-demographic characteristics. For any fertility preference and religious status, the median is the same (one child) irrespective of the migration status. However, there are some differentiation. Taking into account the fertility preference and the religion, recent migrants generally have higher births over the past five years than non-migrants and earlier migrants. The value of the third quartile among recent migrants ( 2 children) is higher than that among non-migrants and earlier migrants for both Muslim and non-Muslim women. With regard to education, the number of childbirths over the past five years decreases as the educational level increases, only among earlier migrants. Finally, using modern methods of contraception is associated with the lowest births over the past five years among earlier migrant women unlike among recent migrant women. 



Figure 1: Distribution of the number of births in the last five years preceding the survey by socioeconomic and socio-demographic characteristics and according to the migration status.

Table 3 presents the multivariate analysis results that allow to testing the net effect of the internal migration on fertility. The figures presented for all variables across the models are coefficients obtained from Tobit estimations. Different models are computed in order to test the hypotheses expressed earlier. Three different models are thus generated based on variables which can be summarized as follows.

Model I Migration status taking into account the duration of the migration. This model shows the relationship between migration and fertility in the absence of any other socio-economic and socio- 
demographic variables. In consequence, it gives an insight into the adaptation hypothesis (Hypothesis Ia and Hypothesis Ib) testing.

Model 2 Model I plus four socio-economic and socio-demographic variables: educational level, fertility preference (through the ideal number of children), contraceptive use and religion of the woman. The hypothesis of selection (Hypothesis 2 ) is tested through this model.

Model 3 In this model, migration status is replaced by an interaction variable which represents the combination of migration status and the motive of living in the current location (work/school or neither work nor school). Then, the age of the woman is added. Model 3 allows to testing Hypothesis 3 (disruption hypothesis).

The p-value $<0.00$ I (for every model in Table 3) makes conclude that each global model fits significantly better than an empty model; that is, a model with no predictor. First, results from Model I show that recent migrant women have a higher number of births over the past five years than nonmigrant and earlier migrant women. At I percent level of significance, the formers (recent migrant women) have 0.39 more children than the latter (non-migrant and earlier migrant women), which confirms the initial process of adaptation (Hypothesis la). Then, there is no significant difference between earlier migrant and non-migrant women suggesting the confirmation of the last process of adaptation (Hypothesis Ib). In sum, these results prove that the adaptation process is gradual and is a long-term rather than a short-term prospect. So, migrants exhibit lower fertility (over the past five years) similar to that of non-migrants in Cotonou as time spent increases.

Next, women's background variables are included in the analysis to further control for sociodemographic and socio-economic selectivity when assessing the effect of migration on fertility. The differences outlined above decrease slightly, but the significance remains unchanged (Table 3, Model 2). Thus, the analysis supports previous findings: gradual adaptation. Migrants initially experience higher fertility than non-migrants and then, adapt to the latter' lower fertility pattern after a certain amount of time of adaptation. The major task is now to clarify why the fertility of earlier migrant women is similar to that of non-migrant women in Cotonou. This result may be due to migrant women' adaptation, or a rather further selectivity of migrant women that is unobserved in this case.

Model 2 fit improves significantly. Indeed, the likelihood ratio test statistic value has increased from I 4.38 in Model I to 43.12 in Model 2 with p-values of 0.0008 and 0.0000 respectively. Furthermore, the coefficient has significantly decreased in Model 2 for recent migrants and is close to zero (although nonsignificant) for earlier migrants. Thus, migrant women (some of them, at least) have unobserved characteristics that decrease their births over the past five years. Controlling for this unobserved selectivity, however, does not change the previous results substantially. It can be established that some migrations are directly related to the delay in childbearing. Also, strong positive selection of migrant women by fertility preferences operates towards migrating to Cotonou. In other words, the figures obtained from Model 2 is supportive of the selection hypothesis, but the adaptation hypothesis still holds.

So far, it has been assumed a lower fertility among recent migrants for job or school motive, comparatively to non-migrant and earlier migrant. To verify the validity of this assumption, interaction terms between the migration status and the motive of leaving at the current location are included. This strategy enables to examine the disruption hypothesis in more detail. It also allows to gaining further insight into the selectivity issue. The effects of the different interaction terms on the number of births over the past five years are presented in Figure 2. It is noticed that recent migrant women who have migrated for work or school reason have the lowest significant fertility. Which gives support to the disruption hypothesis. On the other hand, women of all other categories have similar fertility (Figure 2). This comprises non-migrants and earlier migrants as well as recent migrants for any other reason than work or school. This similarity may be due to adaptation. The model fit, however, improves considerably (likelihood ratio of $345.7 \mathrm{I}$ and $\mathrm{p}$-value is 0.000 ), pointing out the validity of the selection hypothesis. 
Table 3: Number of births in the last 5 years preceding the survey: results of Tobit estimations

\begin{tabular}{|c|c|c|c|}
\hline Variables & Model 1 & Model 2 & Model 3 \\
\hline variabies & Coefficients & Coefficients & Coefficients \\
\hline $\begin{array}{l}\text { Migration status } \\
\text { Non-migrant } \\
\text { Recent migrant } \\
\text { Less recent migrant }\end{array}$ & $\begin{array}{l}\text { Ref. } \\
0.39^{\star \star \star} \\
0.06\end{array}$ & $\begin{array}{l}\text { Ref. } \\
0.36^{\star * *} \\
0.02\end{array}$ & \\
\hline 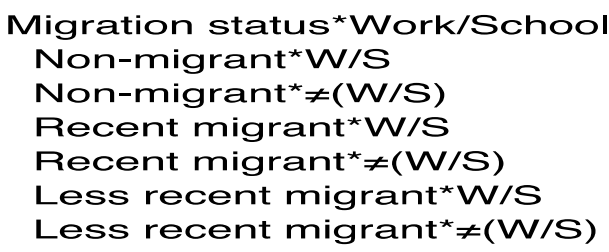 & (1) & & $\begin{array}{l}\text { Ref. } \\
-0.15 \\
-0.79^{\star \star} \\
-0.02 \\
0.22 \\
-0.04\end{array}$ \\
\hline $\begin{array}{l}\text { Educational level } \\
\text { No education } \\
\text { Primary } \\
\text { Secondary or higher }\end{array}$ & & $\begin{array}{l}\text { Ref. } \\
-0.12 \\
-0.11\end{array}$ & $\begin{array}{r}\text { Ref. } \\
-0.13 \\
0.04\end{array}$ \\
\hline $\begin{array}{l}\text { Ideal number of children } \\
\text { Less than } 4 \\
4 \text { or above }\end{array}$ & & $\begin{array}{l}\text { Ref. } \\
0.34^{\star * \star}\end{array}$ & $\begin{array}{l}\text { Ref. } \\
0.26^{\star * *}\end{array}$ \\
\hline $\begin{array}{l}\text { Contraceptive use } \\
\text { No method } \\
\text { Traditional } \\
\text { Modern }\end{array}$ & & $\begin{array}{l}\text { Ref. } \\
0.22 \\
0.41^{* * *}\end{array}$ & $\begin{array}{l}\text { Ref. } \\
0.19 \\
0.28^{\star * *}\end{array}$ \\
\hline $\begin{array}{l}\text { Religion (Muslim or not) } \\
\text { Muslim } \\
\text { Non-Muslim }\end{array}$ & & $\begin{array}{l}\text { Ref. } \\
-0.02\end{array}$ & $\begin{array}{r}\text { Ref. } \\
\text {-0.01 }\end{array}$ \\
\hline Age (in years) & & & $-0.10^{\star \star \star}$ \\
\hline Constant & $0.48^{\star \star \star}$ & $0.30^{\star}$ & $4.04^{\star \star \star}$ \\
\hline $\begin{array}{l}\text { Observations } \\
\text { Degree of freedom } \\
\text { Likelihood ratio } \\
\text { P-value }\end{array}$ & $\begin{array}{l}722 \\
2 \\
14.38 \\
0.0008\end{array}$ & $\begin{array}{l}722 \\
8 \\
43.12 \\
0.0000\end{array}$ & $\begin{array}{l}722 \\
12 \\
345.71 \\
0.0000\end{array}$ \\
\hline
\end{tabular}

W/S $=$ who are in Cotonou for work or school reason

$\neq(W / S)=$ who are in Cotonou neither for work nor for school reason

Ref. = reference category; ${ }^{\star \star \star} p<0.01,{ }^{\star \star} p<0.05,{ }^{*} p<0.1$

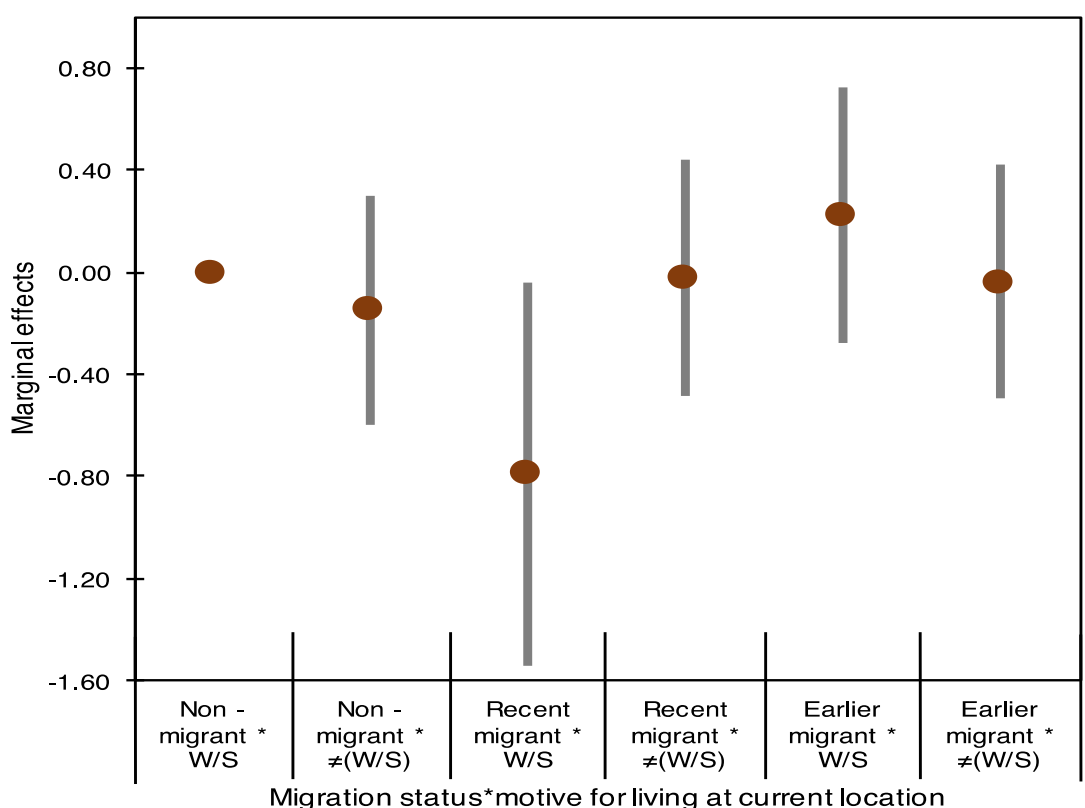

$\mathrm{W} / \mathrm{S}=$ who are in Cotonou for work or school reason

$\neq(\mathrm{W} / \mathrm{S})=$ who are in Cotonou neither for work nor for school reason

Source: Author's calculations based on the Benin Republic 2012 DHS 
Figure 2: Effect of migration on the number of births over the past five years in Cotonou, Benin Republic. Marginal effects of interaction terms between migration status and motive for living at the current location (work/school)

Finally, as for the other control variables, findings concerning fertility preference and age are as expected. The older generations of women have a higher number of births over the past five years than the younger ones. The estimate is a reduction of 0.10 child over the past five years per one-year increase in the age, all other factors being equal. Women who express a high fertility preference have higher fertility over the past five years than their peers who desire a lower number of children. In particular, women who desire more than three children (in their reproductive life) have 0.26 more child (over the past five years) than those who desire less than 4 children, other things being equal. Educational level and religious status (being Muslim or not) do not affect significantly the number of births over the past five years preceding the survey. However, in a less than expected way, using modern contraceptive does not seem to contribute significantly to the decline in the number of births. Women who were using modern contraceptive have higher number of births over the past five years than those not using it. A higher number of births over the past five years among modern contraceptive users is observed only among recent migrant women (see Figure I). This may suggest that, like many rural women, those who recently migrated to Cotonou generally failed to use adequately modern methods of contraception. The contraceptive failure is often due to a lack of knowledge about the use as women take time to adapt to the new urban environment.

\section{Discussion and conclusion}

This study investigates the relationship between migration and fertility in Cotonou, the largest city of Benin Republic. The 2012 DHS data are used to investigate the effect of migration on the number of births in the five years prior to the survey. The target population is women who were married at least five years before the survey and living in Cotonou at the moment of the DHS. Through Tobit estimations, three different models are set out to test the adaptation hypothesis (Table 3, Model I), the selection hypothesis (Table 3, Model 2) and the disruption hypothesis (Table 3, Model 3).

First, the modelling began by examining the differences in the number of births in the five years before the survey between migrant and non-migrant women. The analysis firstly showed that the number of births is significantly higher among recent migrant women than earlier migrant and non-migrant women. Residents of Cotonou had a significantly lower number of births over the past five years, as compared to recent migrant women. The findings secondly showed that migrant women who have spent a least ten years in Cotonou exhibit similar fertility levels as the non-migrants. So, migrant women do not immediately adapt to the new urban environment, but rather after a certain period of time of stay in Cotonou. The adaptation to the lower fertility pattern in Cotonou among migrant women is then a gradual process that takes time.

Then, the relationship between migration and fertility was controlled for socio-economic and demographic selectivity of migrant women. Patterns observed in the previous step changed slightly, but not significantly. The analysis highlighted the presence of unobserved selectivity for migrants to Cotonou. However, previous results did not alter much. On the one hand, earlier migrant women still exhibited rather similar fertility levels as the non-migrants in Cotonou. On the other hand, the fertility differential between recent migrant and non-migrant women decreased further. Finally, to test the disruption hypothesis, interaction terms between migration status and the motive of leaving at the current location were included in the previous model (Model 2). It was found that recent migrant women in Cotonou for job or school reason have the lowest number of births over the past five years. This is evidence of disruption model confirmation.

Figures obtained from the initial model are consistent with a gradual process of migrants' adaptation. Adaptation hypothesis underlines the importance of the new environment and its effects on migrants' behaviours. Dominant values and norms in the new environment shape migrants' social and reproductive behaviours. But, it takes times for migrants, to adapt to new values and norms. Thus, migrants' behaviours converge with that of natives in the new environment after a period of time as proved by some recent studies (Kulu, 2006; Afulani \& Asunka, 2015; Kulu et al., 2017). The adaptation itself works through a diffusion of the new environment's contraceptive and fertility practices from native to migrants at the place of destination (Ochako et al., 2016; Selassie, 2017). This adaptation is essentially fed in urban areas by access to mass education and other economic opportunities. In urban areas, mass education changes the values and costs of children within the family and introduces a Western family model into society (Westoff et al., 2013). Kamruzzaman and Hakim (20I5) found in Bangladesh that urban areas provide greater exposure to information about family planning and fertility practices through print and broadcast media; what leads to lower fertility. Migrants to large cities, 
however, do not immediately adapt to the new situation. They rather accumulate knowledge over time as they learn more about their new environment and expand their range of social contacts (Uprety et al., 2016).

Second, when controlling for socio-economic and socio-demographic factors, the model fit improved. The intensity of the relationship between migration and fertility became weak, which may reflect a migrant selection. Migrant selection effect proposes that migrants are a self-selecting group with specific characteristics that cause a delay in marriage and childbearing (Chattopadhyay et al., 2006). One of the main explanation may be that women who migrate to Cotonou are not randomly constituted. Instead, they have certain socio-economic and socio-demographic traits associated with low fertility preference. Generally, migrants in Cotonou are more educated, have high access to media. Most of them usually move to Cotonou for job and school opportunities as well as other economic reasons. This explanation found support in a study by Rokicki et al. (2014) on the association between migration and pregnancy outcomes among women in urban slums of Accra.

However, the selection hypothesis is not enough strong to the point to reject its complementarity with that of adaptation as found in previous studies (Chattopadhyay et al., 2006; Lindstrom \& Hernández, 2006; Rokicki et al., 20I4; Ochako et al., 2016). This complementarity can be incriminated to explain the similarity in the number of births between earlier migrants and non-migrants in Cotonou. This finding supports that of Rokicki et al. (20/4) when justifying the similarity in the completed fertility between migrants and natives in Accra. As suggested by the authors, it can also be argued that rural-urban migrants are more likely to have a desired fertility similar to that of natives. Migrants may seek easier access to modern contraception that can help them reduce their family size. But, the likelihood of contraceptive failure may be higher among (newcomers) recent migrants, and consequently, lead to a higher number of births comparatively to nonmigrants. Then, after a long period spent in Cotonou, they experience a greater expertise in modern contraceptive use; which can contribute to a lower fertility, similar to that of non-migrants in Cotonou. Migrants in Cotonou may desire to invest in better educational opportunities for their children and thus desire a smaller number of children to invest in. They may also be looking for paid employment, which can delay childbearing. Alternatively, migrants gradually adapt to their new surroundings and adjust their fertility behaviour to match that of urban natives at the destination place.
Third, the lowest number of births over the past five years among recent migrants for work or school reason strongly suggests the possibility of disruption. Indeed, the migration process itself may be disruptive of fertility, although the resulting delay in childbearing may be compensated for after a longer period of settlement (Sargent \& Cordell, 2003; Chattopadhyay et al., 2006). This possibility may account for the quite similar fertility levels of long-term migrants and of non-migrants in Cotonou. What helps account to confirm the disruption hypothesis in this study is the lowest number of births among recent migrant for employment or school motive. Moreover, the other groups experience similar fertility pattern. Therefore, it can be argued that newcomers for job or school reason delay their childbearing in order to achieve their main goal (work or studies). Then, after a certain period of settlement in Cotonou, the latter adapt so that, non-migrants and now-earlier migrants have similar fertility.

On the other hand, there may be reasons for the disruptive character of the migration process, especially when taking into account the reason for migration. The move for economic reasons may be sufficiently disruptive from a socio-psychological perspective such as interfering with the physiological capacity to conceive and bear children (Rutayisire, 2015; Goldberg et al., 2017). But, the disruption may also directly operate through spousal separation. A previous research conducted by Philibert et al. (20I3) among migrants in Kayes, Mali, suggested that migration involves an initial period of separation between spouses. The duration that period of time, migrant women are less exposed to pregnancies. This may also be the case for migrant women in Cotonou who, while married, were living alone, at least for a short period. These women who mostly move for job or school reason, are more likely to have a considerably lower fertility than those with spouse presence. In other words, spousal separation also contributes to the lower number of births among recent migrant women for employment or school motive.

The key strength of this study is that it eliminates the endogeneity issue which might bias the estimations results. Indeed, when analysing the relationship between migration and fertility, it is difficult to determine its direction of causality. That is: (I) Do births make women more likely to migrate out again? (2) Or rather, does giving birth mean that women become less mobile? If the first condition is met, the true impact of migration may be underestimated. Otherwise, the opposite would be true. In short, the results are representative only of women who stay long enough in Cotonou for observing fertility. To address this endogeneity 
problem, it was decided to use the number of births over the past five years as a fertility indicator. Then, migrants who spent less than five years in Cotonou are excluded. Doing so, it is ensured that migration status is properly considered here as the probable cause of fertility; what the study intended to seek.

However, this study has several limitations. Although the level of detail of the data in regards to migration and fertility is high in comparison with other countries' DHS data, potential biases remain. First, the data represent the average population of Cotonou at a given point in time. By definition, this includes women who just moved into Cotonou, and women who move out of Cotonou are not included. Thus, the results are representative only of women who stay long enough in Cotonou for observing the past five years childbirths. Moreover, the study focused on women while it may be more interesting to include male fertility behaviours as their involvement contributes to the fertility level. Furthermore, most of the migration decisions are made either by men or by both women and men in Sub-Saharan Africa context. An event-history approach with rich retrospective data would enable to examine more closely the effects of various migrations and time at destination on migrants' fertility. The main evidence of this study is that migration affects fertility.

\section{Reference}

Afulani, P. A. \& Asunka, J. 2015. Socialization, adaptation, transnationalism, and the reproductive behavior of sub-Saharan African migrants in France. Population Research and Policy Review, 34, 56I-592.

Agadjanian, V., Yabiku, S. T. \& Cau, B. 20I I. Men's migration and women's fertility in rural Mozambique. Demography, 48, I029-1048.

Andersson, G. 2004. Childbearing after Migration: Fertility Patterns of Foreign-born Women in Sweden. International Migration Review, 38, 747774.

Anglewicz, P., Corker, J. \& Kayembe, P. 2017. The fertility of internal migrants to Kinshasa. Genus, 73, 4.

Avogo, W. \& Agadjanian, V. 2008. Childbearing in crisis: War, migration and fertility in Angola. Journal of Biosocial Science, 40, 725-742.

Babatunde, S. S. \& Ibukun, A. A. 2017. determinants of contraceptive use among hausa migrants in selected urban communities of osun state, Nigeria. Ife PsychologIA, 25.

Beine, M., Docquier, F. \& Schiff, M. 2013. International migration, transfer of norms and home country fertility. Canadian Journal of
Economics/Revue canadienne d'économique, 46, I406-I430.

Benza, M., Weeks, J. R., Stow, D. A., López-Carr, D. \& Clarke, K. C. 2017. Fertility and urban context: A case study from Ghana, West Africa, using remotely sensed imagery and GIS. Population, Space and Place.

Bourbonnais, R. 2009. Économétrie-7e édition, Dunod.

Brockerhoff, M. 1995. Fertility and family planning in African cities: The impact of female migration. Journal of Biosocial Science, 27, 347-358.

Brockerhoff, M. 1998. Migration and the fertility transition in African cities. Migration, urbanization, and development: new directions and issues, 35787.

Brockerhoff, M. \& Eu, H. 1993. Demographic and socioeconomic determinants of female rural to urban migration in Sub-Saharan Africa. International Migration Review, 557-577.

Brockerhoff, M. \& Yang, X. 1994. Impact of migration on fertility in sub-Saharan Africa. Social Biology, 4I, 19-43.

Byass, P., Alberts, M. \& Burger, S. 2011. Motherhood, migration and mortality in Dikgale: modelling life events among women in a rural South African community. Public health, 125, 318323.

Cau, B. M. 2016. Female migration, local context and contraception use in urban Mozambique. African Journal of Reproductive Health, 20, 52-6I.

Chattopadhyay, A., White, M. J. \& Debpuur, C. 2006. Migrant fertility in Ghana: Selection versus adaptation and disruption as causal mechanisms. Population studies, 60, 189-203.

Chintsanya, J. 2013. Trends and correlates of contraceptive use among married women in Malawi: Evidence from 2000-2010 Malawi Demographic and Health Surveys. DHS Working Papers No. 87. Calverton, Maryland, USA: ICF International.

Coburn, C., Reed, H. E., Restivo, M. \& Shandra, J. M. The World Bank, Organized Hypocrisy, and Women's Health: A Cross-National Analysis of Maternal Mortality in Sub-Saharan Africa. Sociological Forum, 2017. Wiley Online Library, 50-7I.

De Brauw, A., Mueller, V. \& Lee, H. L. 2014. The role of rural-urban migration in the structural transformation of Sub-Saharan Africa. World Development, 63, 33-42.

Dupray, A. \& Pailhé, A. 2017. Does employment uncertainty particularly impact fertility of children of North African immigrants in France? A gender perspective. Journal of Ethnic and Migration Studies, I-24. 
Ellawela, Y., Nilaweera, I., Holton, S., Rowe, H., Kirkman, M., Jordan, L., Mcnamee, K., Bayly, C., Mcbain, J. \& Sinnott, V. 2017. Contraceptive use and contraceptive health care needs among Sri Lankan migrants living in Australia: Findings from the understanding fertility management in contemporary Australia survey. Sexual \& Reproductive Healthcare, 12, 70-75.

Engel, E., Richter, D. \& Schüring, J. 2017. Bénin: vers une transformation rurale inclusive et durable.

Fincher, R. A. 1994. International Conference on Population and Development. Envtl. Pol'y \& L., 24, 309.

Flückiger, M. \& Ludwig, M. 2017. Urbanization, fertility and child education in Sub-Saharan Africa. Economics Letters.

Garenne, M. 2013. Situations of fertility stall in subSaharan Africa. African Population Studies, 23.

Goldberg, R. E., Tienda, M. \& Adserà, A. 2017. Age at migration, family instability, and timing of sexual onset. Social science research, 63, 292-307.

Goldstein, S. \& Tirasawat, P. 1977. Fertility of migrants to urban places in Thailand.

Gries, T. \& Grundmann, R. 20/5. Fertility and modernization: the role of urbanization in developing countries. Journal of International Development.

Hervitz, H. M. 1985. Selectivity, adaptation, or disruption? A comparison of alternative hypotheses on the effects of migration on fertility: The case of Brazil. International Migration Review, 293-317.

Insae 2016. Principaux Indicateurs Socio démographiques et Économiques du Bénin, (RGPH-4, 20I3).

Insae \& Icf International 2013. Enquête Démographique et de Santé Bénin 20II-20I2. Calverton, Maryland, USA: INSAE/Bénin and ICF International.

Jann, B. 20/4. Plotting regression coefficients and other estimates in Stata.

Jedwab, R., Christiaensen, L. \& Gindelsky, M. 2017. Demography, urbanization and development: Rural push, urban pull and... urban push? Journal of Urban Economics, 98, 6-I6.

Kamruzzaman, M. \& Hakim, M. A. 20I5. Family Planning Practices among Married Women attending Primary Health Care Centers in Bangladesh. International Journal of Bioinformatics and Biomedical Engineering, I, 25 I-255.

Kulu, H. 2006. Fertility of internal migrants: comparison between Austria and Poland. Population, space and place, 12, 147-170.

Kulu, H., Hannemann, T., Pailhé, A., Neels, K., Krapf, S., González-Ferrer, A. \& Andersson, G. 2017. Fertility by birth order among the descendants of immigrants in selected European countries. Population and Development Review, 43, 31-60.

Leibenstein, H. \& Leibenstein, H. 1963. Economic backwardness and economic growth: studies in the theory of economic development.

Lindstrom, D. P. \& Hernández, C. H. 2006. Internal migration and contraceptive knowledge and use in Guatemala. International family planning perspectives, I46-I53.

Majelantle, R. \& Navaneetham, K. 2013. Migration and Fertility: A Review of Theories and Evidences. J Glob Econ, I, 2.

Marcén, M., Molina, J. A. \& Morales, M. 2016. The effect of culture on the fertility decisions of immigrant women in the United States.

Mberu, B., Béguy, D. \& Ezeh, A. C. 2017. Internal Migration, Urbanization and Slums in Sub-Saharan Africa. Africa's Population: In Search of a Demographic Dividend. Springer.

Mberu, B. U., Ciera, J. M., Elungata, P. \& Ezeh, A. C. 2016. Fertility and Household Economic Outcomes among Poor Urban Households in Nairobi informal Settlements, Kenya. Etude de la Population Africaine, 30.

Michel, A. \& Ribardière, A. 2017. Identifier les ressources urbaines pour lire les inégalités sociospatiales. Introduction. EchoGéo.

Ochako, R., Askew, I., Okal, J., Oucho, J. \& Temmerman, M. 2016. Modern contraceptive use among migrant and non-migrant women in Kenya. Reproductive health, 13, 67.

Odimegwu, C. \& Somefun, O. D. 2017. Background Family planning interventions are cost-effective and have several cross-cutting benefits. Despite these benefits of family planning, progress in ensuring universal access to family planning to women in developing countries has been slow. In light of this; this study investigated the prevalence and factors associated with contraceptive use in Tigray Region, Northern Ethiopia. Methods A. Reproductive Health, I4, I-II.

Pailhé, A. 2017. The convergence of secondgeneration immigrants' fertility patterns in France: The role of sociocultural distance between parents' and host country. Demographic Research, 36, I36I-I 398.

Philibert, A., Tourigny, C., Coulibaly, A. \& Fournier, P. 2013. Birth seasonality as a response to a changing rural environment (Kayes region, Mali). Journal of biosocial science, 45, 547-565.

Rokicki, S., Montana, L. \& Fink, G. 20I4. Impact of migration on fertility and abortion: evidence from the household and welfare study of Accra. Demography, 5I, 2229-2254. 
Rutayisire, P. C. 2015. Disruptive Events and Demographic Behaviour: Explaining the Shifts in Fertility in Rwanda, Utrecht University.

Sargent, C. \& Cordell, D. 2003. Polygamy, disrupted reproduction, and the state: Malian migrants in Paris, France. Social science \& medicine, 56, 19611972.

Schoumaker, B. 2013. A Stata module for computing fertility rates and TFRs from birth histories: tfr2. Demographic Research, 28, 1093-I I 44.

Selassie, T. G. 2017. Determinants of contraceptive use among urban youth in Ethiopia. The Ethiopian Journal of Health Development (EJHD), 10.

Shapiro, D. \& Gebreselassie, T. 2013. Fertility transition in sub-Saharan Africa: falling and stalling. African Population Studies, 23.

Singley, S. G. \& Landale, N. S. 1998. Incorporating origin and process in migration-fertility frameworks: The case of Puerto Rican women. Social Forces, 76, I437-| 464.

United Nations 2014. World Urbanization Prospects The 20I4 Revision.

Uprety, S., Khatri, R., Baral, S. C., Regmi, S. \& Macdonald, M. 2016. Access to family planning services by migrant couples in Nepal-barriers and evidence gaps.

Westoff, C. F., Bietsch, K. \& Hong, R. 2013. Reproductive preferences in Cambodia: Further analysis of the Cambodia Demographic and Health Surveys. DHS Further Analysis Reports No. 87. Calverton, Maryland, USA: ICF International.

Williams, J., Ibisomi, L., Sartorius, B., Kahn, K., Collinson, M., Tollman, S. \& Garenne, M. 2013. Convergence in fertility of South Africans and Mozambicans in rural South Africa, 1993-2009. Global health action, 6, 19236.

Wulifan, J. K., Mazalale, J., Jahn, A., Hien, H., Ilboudo, P. C., Meda, N., Robyn, P. J., Hamadou, S., Haidara, O. \& De Allegri, M. 2017. Factors Associated with Contraceptive Use among Women of Reproductive Age in Rural Districts of Burkina Faso. Journal of Health Care for the Poor and Underserved, 28, 228-247.

Yabiku, S. T., Agadjanian, V. \& Sevoyan, A. 2010. Husbands' labour migration and wives' autonomy, Mozambique 2000-2006. Population studies, 64, 293-306.

Zamwangana, T. 2005. Migration féminine et fécondité à Kinshasa. These de doctorat, Université catholique de Louvain, Institut de Démographie. Louvain-la-Neuve: AcademiaBruylant.

Zinkina, J. \& Korotayev, A. 20I4. Explosive population growth in tropical Africa: crucial omission in development forecasts-emerging risks and way out. World Futures, 70, I 20-I 39. 